\begin{tabular}{l} 
DURNAI, R IS'T \\
(Rekayasa Sistem dan Teknologi Informasi) \\
Vol.3 No.2 (2019) $2010-2015 \quad$ ISSN Media Elektronik: 2580-0760 \\
\hline
\end{tabular}

\title{
Perancangan Enterprise Architecture Pada Bidang Agroforestry Menggunakan Metode Togaf 9.1 Adm
}

\author{
Ega Silvana Almunadia ${ }^{1}$, Tien Fabrianti Kusumasari ${ }^{2}$, Iqbal Santosa ${ }^{3}$ \\ ${ }^{1,2,3}$ Prodi S1 Sistem Informasi, Fakultas Rekayasa Industri, Universitas Telkom \\ 1egaalmunadia@student.telkomuniversity.ac.id
}

\begin{abstract}
Perum Perhutani is a State-Owned Enterprise (SOE) that focus on forest management. One of the Perum Perhutani's main businesses is Agroforestry. To achieve the business goals of Agroforestry, Perum Perhutani requires an information system that is capable of supporting its management activities. In developing IT, Perum Perhutani has a reference, that is the SOE Regulation Number: PER-03 / MBU / 02/2018 regarding the Information Technology Management Preparation Guide that every BUMN must align business strategy with the IT strategy. So, Perum Perhutani requires the design of Enterprise Architecture. The framework that will be used in designing Enterprise Architecture is the Open Group Architecture Framework (TOGAF) and the TOGAF Architecture Development Method (ADM) method. The output of this design is a blueprint and IT Roadmap for 5 years that can be used as an implementation guide.
\end{abstract}

Keywords: Enterprise Architecture Design, TOGAF, TOGAF ADM, Agroforestry Information System, Information System Architecture.

\begin{abstract}
Abstrak
Perum Perhutani merupakan Badan Usaha Milik Negara (BUMN) yang bergerak dibidang pengelolaan hutan. Salah satu bisnis utama yang dikembangkan oleh Perum Perhutani adalah Agroforestry. Untuk mencapai sasaran bisnis dari Agroforestry, Perum Perhutani membutuhkan sistem informasi yang mampu menunjang kegiatan pengelolaannya. Dalam melakukan pengembangan TI, Perum Perhutani memiliki acuan yaitu Peraturan Menteri BUMN Nomor : PER03/MBU/02/2018 tentang Panduan Penyusunan Pengelolaan Teknologi Informasi dimana setiap BUMN harus menyelaraskan strategi bisnis dengan strategi TI perusahan. Sehingga, Perum Perhutani membutuhkan perancangan Enterprise Architecture. Framework yang akan digunakan dalam perancangan Enterprise Architecture ini adalah The Open Group Architecture Framework (TOGAF) dan metode TOGAF Architecture Development Method (ADM). Output dari perancangan ini berupa blueprint dan IT Roadmap selama 5 tahun yang dapat digunakan sebagai panduan implementasi.
\end{abstract}

Kata kunci: Perancangan Enterprise Architecture, TOGAF, TOGAF ADM, Sistem Informasi Agroforestry, Arsitektur Sistem Informasi.

(C) 2019 Jurnal RESTI

\section{Pendahuluan}

Pada era digitalisasi seperti sekarang ini, teknologi informasi (TI) semakin berkembang dan memiliki peran yang sangat penting dalam kehidupan manusia. Peranan TI untuk setiap aktivitas perusahaan sangatlah penting karena dapat membantu perusahaan untuk mencapai tujuannya. Tetapi pengembangan TI harus selaras dengan strategi bisnis perusahaan sebagai salah satu cara untuk mencapai sasaran strategi bisnisnya dengan efektif dan efisien. Penyelarasan TI dengan strategi bisnis dalam perusahaan adalah salah satu tujuan utama dari penerapan Enterprise Architecture (EA). Enterprise architecture dapat diartikan sebagai sebuah praktek yang terdefinisi dengan baik untuk menjalankan perusahaan mulai dari analisis, desain, perencanaan dan implementasi [1].

Perusahaan Hutan Negara Indonesia (Perhutani) merupakan Badan Usaha Milik Negara (BUMN) berbentuk Perusahaan Umum (Perum) sebagai pengelola hutan yang memiliki peran strategis mendukung sistem kelestarian lingkungan, sosial budaya dan perekonomian masyarakat kehutanan

Diterima Redaksi : 01-07-2019 | Selesai Revisi : 20-07-2019 | Diterbitkan Online : 03-08-2019 
nasional. Perum Perhutani membagi proses bisnisnya ke dalam 3 aktivitas, yaitu aktivitas utama, aktivitas bisnis dan aktivitas pendukung. Aktivitas utama yaitu pengelolaan sumber daya hutan, produksi hasil hutan dan kemanfaatan umum. Sedangkan aktivitas bisnis merupakan kegiatan pemasaran, industri, dan wisata. Dan aktivitas pendukung merupakan kegiatan pendukung perusahaan seperti perencanaan dan pengembangan bisnis, Sumber Daya Manusia (SDM) dan umum, keuangan serta penelitian dan pengembangan Sumber Daya Hutan (SDH) [8].

Keadaan sistem informasi pada Perum Perhutani saat ini hanya mendukung kegiatan utama saja yaitu kayu. Untuk kagiatan bisnis lainnya seperti agroforestry, non kayu dan wisata belum dikembangkan sistem informasi. Untuk pengelolaan data pun belum ditetapkan pengelolaan secara terpusat dan pertukaran data tidak dilakukan secara elektronik. Sehingga setiap kegiatan proses bisnis dirasa kurang efektif dan efisien. Berdasarkan keaadan saat ini, Perum Perhutani membutuhkan sistem informasi untuk dapat mendukung setiap kegiatan bisnisnya. Pengembangan sistem informai harus selaras dengan strategi bisnis perusahaan sesuai dengan Peraturan Menteri BUMN Nomor: PER03/MBU/02/2018 tentang panduan penyusunan pengelolaan teknologi informasi BUMN yang bertujuan agar perencanaan TI selaras perencanaan dan tujuan bisnis BUMN.

Perancangan Enterprise Architecture dapat menjadi solusi yang tepat untuk menyelaraskan strategi TI dengan strategi bisnis pada perusahaan. Enterprise Architecture dapat membantu perusahaan mendefisikan arsitektur bisnis, sistem informasi dan teknologi yang mampu menyelaraskan strategi bisnis dengan perkembangan TI [1]. Sehingga agar penerapan sistem informasi dapat optimal dan memenuhi kebutuhan bisnis perusahaan, Enterprise Architecture sangat diperlukan. Dalam perancangan Enterprise Architecture membutuhkan sebuah framework atau kerangka kerja yang digunakan sebagai panduan perancangan.

Penelitian ini bertujuan untuk memberikan perancangan Enterprise Architecture pada bagian pengelolaan Agroforestry. Perancangan Enterprise Architecture ini menggunakan framework The Opern Group Framework (TOGAF) karena TOGAF didefinisikan sebagai sebuah kerangka kerja yang menyajikan metode - metode yang sistematis dan peralatan untuk mendukung perancangan EA [2]. Perancangan EA Perum Perhutani menggunakan metode TOGAF Architecture Development Method (ADM). Hasil akhir dari perancangan EA berupa blueprint yang digunakan sebagai panduan dalam membangun TI perusahaan dan IT Roadmap yang digunakan sebagai uraian perencanaan jangka pendek ataupun jangka panjang pengembangan TI.

\section{Metode Penelitian}

Dalam membuat perancangan Enterprise Architecture ini, digunakan metode yaitu TOGAF ADM yang terdiri dari 10 fase. Tetapi pada penelitian ini terbatas pada 4 fase saja yaitu, preliminary phase, architecture vision, business architecture dan information system architecture. Perancangan ini menggunakan tools Modelio 3.7.1 yang telah dilengkapi dengan modul TOGAF Architect. Langkah perancangan ini terbagi menjadi 3 tahap yaitu tahap persiapan dan identifikasi, tahap analisis dan perancangan dan tahap pelaporan yang berisi kesimpulan dan saran. Pada tahap analisis dan perancangan, penulis mengacu pada fase TOGAF ADM sebagai metode yang digunakan. Preliminary phase merupakan persiapan perancangan yang bertujuan untuk menentukan ruang lingkup, arsitektur yang diinginkan perusahaan dan juga prinsip arsitektur yang digunakan sebagai acuan perancangan. Architecture vision merupakan fase awal dari TOGAF ADM yang bertujuan untuk mengembangkan visi arsitektur sesuai dengan nilai bisnis yang akan dicapai. Kemudian business architecture dan information system architecture merupakan fase yang bertujuan untuk mengembangkan arsitektur bisnis dan arsitektur sistem informasi sesuai dengan kebutuhan perusahaan agar tujuan dapat tercapai. Setiap fase dari TOGAF ADM akan menghasilkan output berupa artefak yang terdiri dari katalog, matriks dan diagram. Sistematika penelitian dapat dilihat pada Gambar 1 Sistematika Penelitian.

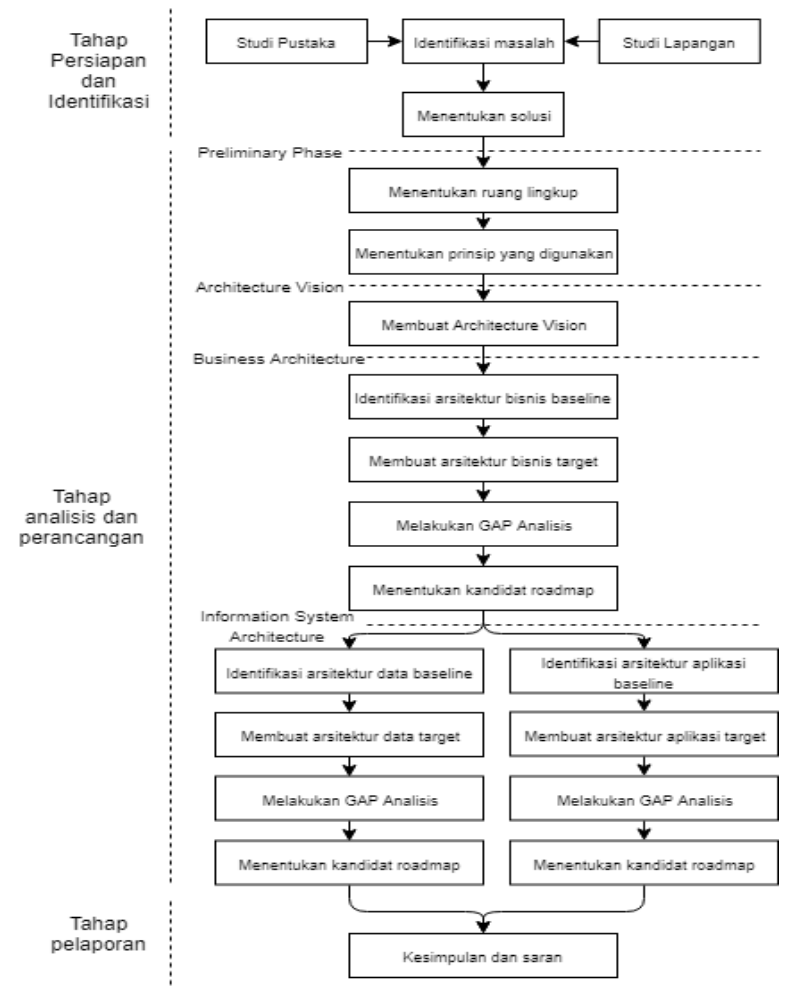

Gambar 1 Sistematika Penelitian

Jurnal RESTI (Rekayasa Sistem dan Teknologi Informasi) Vol . 3 No. 2 (2019) 210 - 215 


\section{Hasil dan Pembahasan}

\subsection{Preliminary Phase}

Preliminary phase merupakan tahap awal sebagai persiapan penyusunan perancangan. Pada tahap ini dilakukan penetapan prinsip yang terdiri dari 4 domain arsitektur yaitu bisnis, data, aplikasi dan teknologi. Prinsip tersebut dapat digunakan sebagai acuan dan alat ukur keberhasilan dari perancangan enterprise architecture [5]. Prinsip yang digunakan dalam perancangan dapat dilihat pada Tabel 1 Principle Catalog di bawah ini:

Tabel 1 Principle Catalog

\begin{tabular}{|c|c|c|}
\hline No & Arsitektur & Prinsip \\
\hline 1 & Bisnis & $\begin{array}{l}\text { Proses bisnis dilakukan seefisien } \\
\text { mungkin }\end{array}$ \\
\hline 2 & Bisnis & Proses bisnis terstandarisasi \\
\hline 3 & $\begin{array}{l}\text { Bisnis, data, } \\
\text { aplikasi, teknologi }\end{array}$ & $\begin{array}{l}\text { Komponen data, aplikasi dan } \\
\text { teknologi dikelola secara terpusat }\end{array}$ \\
\hline 4 & Data, aplikasi & $\begin{array}{l}\text { Pencatatan data hanya dilakukan } \\
\text { satu kali tetapi dapat digunakan } \\
\text { oleh aplikasi lainnya }\end{array}$ \\
\hline & & $\begin{array}{lc}\text { Tidak ada perbedaan data pada } \\
\text { semua } & \text { aplikasi }\end{array}$ \\
\hline 5 & Data & $\begin{array}{l}\text { menggunakannya. Data bersifa } \\
\text { konsisten }\end{array}$ \\
\hline 6 & Data & $\begin{array}{l}\text { Pertukaran data dilakukan melalui } \\
\text { media elektronik dan secara rea } \\
\text { time }\end{array}$ \\
\hline 7 & Aplikasi & Aplikasi mudah dimengerti \\
\hline 8 & Aplikasi, teknologi & $\begin{array}{l}\text { Sistem dapat digunakan dimana } \\
\text { saja dan kapan saja }\end{array}$ \\
\hline 9 & Aplikasi, teknologi & $\begin{array}{l}\text { Sistem TI dilengkapi autentikas } \\
\text { dan autorisasi untuk menentukan } \\
\text { hak akses }\end{array}$ \\
\hline
\end{tabular}

\subsection{Architecture Vision}

Pada fase ini dilakukan pembuatan architecture vision berupa solusi singkat yang akan diberikan pada perusahaan. Gambaran solusi dapat diwakili dengan artefak Solution Concept Diagram. Solusi yang diberikan terdapat pada Gambar 2 Solution Concept Diagram di bawah ini. Solusi yang akan diberikan adalah aplikasi Agroforestry yang dapat diakses oleh divisi yang perencanaan dan pengembangan bisnis dan divisi agroforestry. Aplikasi juga dapat terintegrasi dengan aplikasi untuk mengurangi duplikasi data.

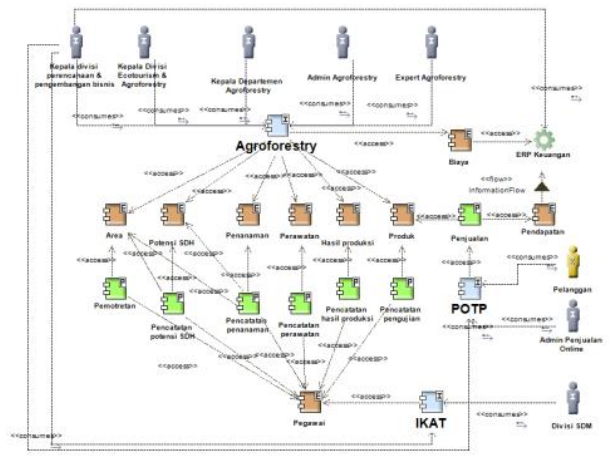

Gambar 2 Solution Concept Diagram

\subsection{Business Architecture}

Pada fase ini dilakukan pembuatan arsitektur bisnis target sesuai dengan kebutuhan bisnis perusahaan untuk mencapai tujuan bisnisnya. Sebelum membuat perancangan arsitektur bisnis target, penulis membuat daftar requirement yang dijelaskan pada Tabel 2 Business Requirement.

Tabel 2 Business Requirement

\begin{tabular}{cl}
\hline No & \multicolumn{1}{c}{ Requirement } \\
\hline 1 & $\begin{array}{l}\text { Strategi bisnis selaras dengan strategi TI } \\
\text { Proses pengelolaan agroforestry berjalan dengan baik } \\
\text { sesuai dengan standar yang berlaku }\end{array}$ \\
3 & $\begin{array}{l}\text { Proses pencatatan data perencanaan dapat digunakan } \\
\text { sebagai informasi untuk melakukan pemanenan }\end{array}$ \\
4 & $\begin{array}{l}\text { Informasi produk yang siap jual dapat digunakan oleh } \\
\text { bagian penjualan }\end{array}$ \\
5 & $\begin{array}{l}\text { Proses pengelolaan agroforestry dapat berjalan dengan } \\
\text { efektif dan efisien }\end{array}$ \\
\hline
\end{tabular}

Salah satu artefak pada fase ini adalah Business Footprint Diagram. Diagram tersebut bertujuan untuk memberikan penjelasan antara komponen agar tujuan bisnis dapat tercapai. Business Footprint Diagram dapat dilihat pada Gambar 3 Business Footprint Diagram.

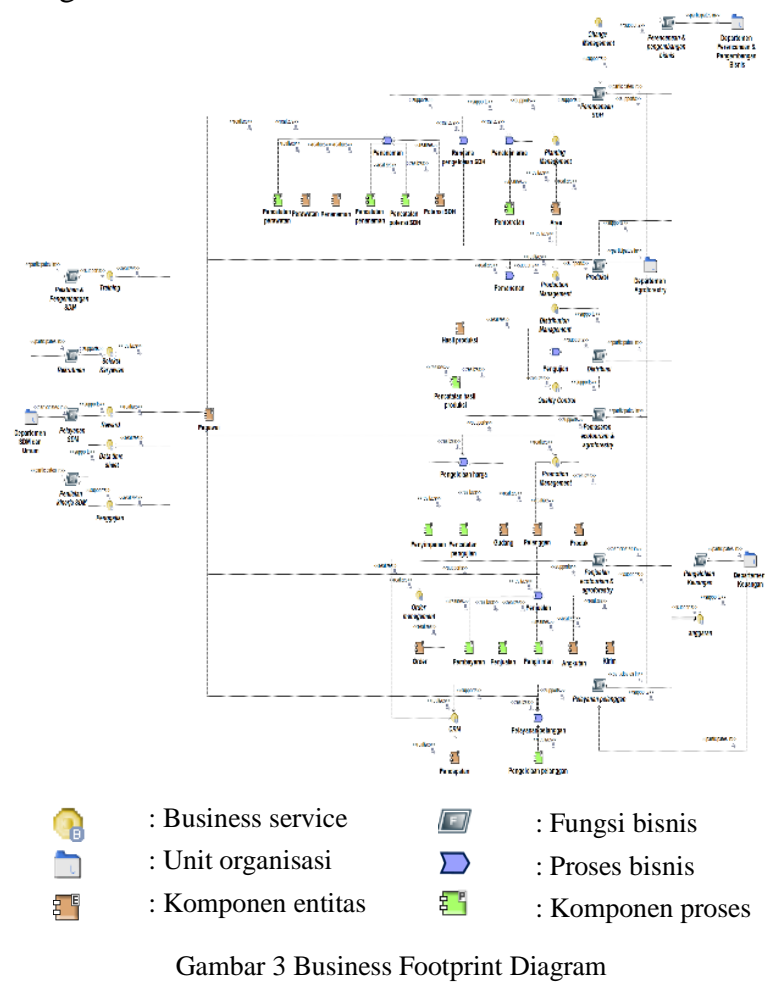

Tabel 3 Goals \& Function merupakan penjabaran goals perusahaan dan peran fungsi bisnis untuk mencapai tujuan tersebut.

\subsection{Information System Architecture - Data} Architecture

Pada fase ini dilakukan perancangan data arsitektur sesuai dengan kebutuhan bisnis perusahaan agar tujuannya dapat tercapai. Sebelum membuat 
perancangan arsitektur data target, penulis membuat daftar requirement yang dijelaskan pada Tabel 4 Data Requirement.

\begin{tabular}{cc} 
Tabel 3 Goals \& Function & \\
\hline Goal & Fungsi \\
\hline Meningkatkan value added pada produk & Perencanaan SDH \\
Goal & Produksi \\
& Distribusi \\
& Fungsi \\
& Perencanaan SDH \\
Meningkatkan pendapatan produk & Produksi \\
& Distribusi \\
& Pemasaran \\
& Penjualan \\
& Pelayanan \\
Meningkatkan pelayanan yang maksimal & pelanggan \\
pada konsumen & Pemasaran \\
& Pelayanan \\
& pelanggan \\
\hline
\end{tabular}

\begin{tabular}{|c|c|}
\hline \multicolumn{2}{|r|}{ Tabel 4 Data Requirement } \\
\hline No & Requirement \\
\hline 1 & $\begin{array}{l}\text { Data dapat digunakan oleh seluruh pengguna yang } \\
\text { membutuhkan sesuai dengan hak akses yang dimiliki }\end{array}$ \\
\hline 2 & Tidak ada duplikasi data \\
\hline 3 & Data terjaga keamananya \\
\hline 4 & $\begin{array}{l}\text { Terdapat sistem pengendalian dan pengelolaan data } \\
\text { terpusat }\end{array}$ \\
\hline 5 & $\begin{array}{l}\text { Proses pengelolaan agroforestry dapat berjalan dengan } \\
\text { efektif dan efisien }\end{array}$ \\
\hline 6 & $\begin{array}{l}\text { Pertukaran dapat dilakukan menggunakan sistem } \\
\text { informasi }\end{array}$ \\
\hline 7 & $\begin{array}{l}\text { Terdapat pembagian hak ases data sesuai dengan } \\
\text { wewenangnya }\end{array}$ \\
\hline 8 & Kerahasiaan data terjaga \\
\hline 9 & Pertukaran data dilakukan secara real-time \\
\hline
\end{tabular}

Perancangan data arsitektur target dapat digambarkan menggunakan artefak bernama conceptual data diagram. Conceptual data diagram bertujuan untuk menampilkan hubungan antara entitas dalam aplikasi yang akan dikembangkan. Conceptual data diagram dapat digambarkan menggunakan Entity Relationship Diagram (ERD). Terdapat 3 komponen pada ERD, yaitu relasi, atribut dan entitas. Entitas merupakan dasar dari sistem dan setiap entitas memiliki atribut sebagai identitas yang membedakan setiap data. setiap hubungan antar entitas digambarkan dengan relasi.

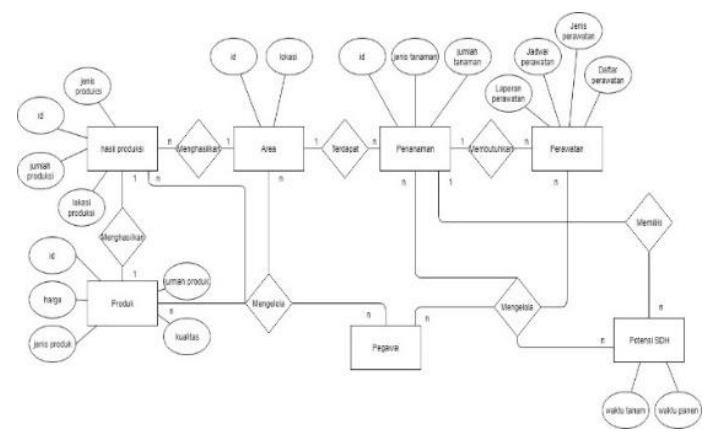

Gambar 4 ERD Agroforestry
Keterangan simbol :

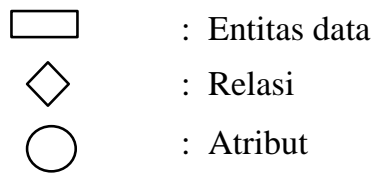

Penjelasan setiap entitas dapat digambarkan menggunakan artefak Data Entity/Data Component Catalog. Katalog tersebut dapat dilihat pada Tabel 5 Data Entity/Data Component Catalog. Terdapat 2 tipe data yaitu master data dan transactional data. master data merupakan induk data yang sering digunakan untuk transactional data sehingga bersifat tetap dan tidak dapat diubah, sedangkan transcational data merupakan data yang dapat berubah.

Tabel 5 Data Entity/Data Component Catalog

\begin{tabular}{ccc}
\hline Entitas & Deskripsi & Tipe \\
\hline Area & Informasi mengenai & Master data \\
& $\begin{array}{c}\text { penatan area penanaman. } \\
\text { Batas hutan dan pembagian } \\
\text { hutan }\end{array}$ & \\
Penanaman & $\begin{array}{c}\text { Informasi mengenai } \\
\text { penanaman }\end{array}$ & Master data \\
Potensi SDH & $\begin{array}{c}\text { Informasi mengenai potensi } \\
\text { SDH yang telah ditanam }\end{array}$ & $\begin{array}{c}\text { Transactional } \\
\text { data }\end{array}$ \\
& Informasi mengenai & Transactional \\
Perawatan & perawatan dan pemeliharan & data \\
& SDH & Transactional \\
Hasil produksi & Informasi mengenai hasil & data \\
Produk & Informasi mengenai produk & Master data \\
& siap jual & \\
\hline
\end{tabular}

3.5 Information System Architecture - Application Architecture

Pada fase ini dilakukan perancangan data arsitektur sesuai dengan kebutuhan bisnis perusahaan agar tujuannya dapat tercapai. Sebelum membuat perancangan arsitektur data target, penulis membuat daftar requirement yang dijelaskan pada Tabel 6 Application Requirement.

Perancangan application architecture dapat digambarkan menggunakan artefak bernama Application Communication Diagram. Diagram tersebut bertujuan untuk menggambarkan dan memetakan komunikasi antar aplikasi. Artefak tersebut dapat dilihat pada Gambar 5 Application Communication Diagram. Terdapat 2 komponen dalam Application Communication Diagram yaitu aplikasi dan entitas data. Komunikasi antar aplikasi digambarkan menggunakan kotak berwarna untuk menunjukkan siapa yang membutuhkan informasi (Required) dan siapa yang menyediakan informasi (Provided). 
Tabel 6 Application Requirement

\begin{tabular}{|c|c|}
\hline No & Requirement \\
\hline 1 & Terdapat aplikasi untuk pengelolaan agroforestry \\
\hline & Aplikasi Agroforetsry terintegrasi dengan aplikasi \\
\hline 2 & $\begin{array}{l}\text { keuangan untuk berbagi data terkait kebutuhan biaya } \\
\text { perencanaan }\end{array}$ \\
\hline 3 & $\begin{array}{l}\text { Aplikasi Agroforestry terintegrasi dengan aplikasi } \\
\text { penjualan online untuk berbagi data terkait produk yang } \\
\text { siap dijual }\end{array}$ \\
\hline 4 & $\begin{array}{l}\text { Aplikasi Agroforestry terintegrasi dengan aplikasi SDM } \\
\text { untuk berbagi data terkait kinerja pegawai sebagai dasar } \\
\text { untuk memberikan gaji }\end{array}$ \\
\hline 5 & $\begin{array}{l}\text { Aplikasi dapat digunakan oleh bagian regional maupun } \\
\text { pusat }\end{array}$ \\
\hline 6 & $\begin{array}{l}\text { Aplikasi dilengkapi autentikasi dan autorisasi untuk } \\
\text { menentukan hak akses pengguna }\end{array}$ \\
\hline 7 & Aplikasi dapat dikelola dan dikendalikan secara terpusat \\
\hline 8 & Aplikasi dapat mempermudah setiap kegiatan agroforestry \\
\hline 9 & Aplikasi dapat menyimpan peta area penanaman \\
\hline 10 & $\begin{array}{l}\text { Aplikasi dapat menyimpan semua informasi terkait } \\
\text { penanaman dan potensi panen dari setiap penanaman }\end{array}$ \\
\hline 11 & $\begin{array}{l}\text { Aplikasi dapat membantu proses pencatatan dan } \\
\text { pengecekan perawatan dari setiap penanaman }\end{array}$ \\
\hline 12 & Aplikasi dapat membantu proses pencatatan hasil produksi \\
\hline 13 & $\begin{array}{l}\text { Aplikasi dapat membantu proses pencatatan produk yang } \\
\text { telah diuji kualitas dan siap untuk dijual }\end{array}$ \\
\hline 14 & $\begin{array}{l}\text { Aplikasi dapat digunakan dengan mudah oleh semua } \\
\text { pengguna }\end{array}$ \\
\hline
\end{tabular}

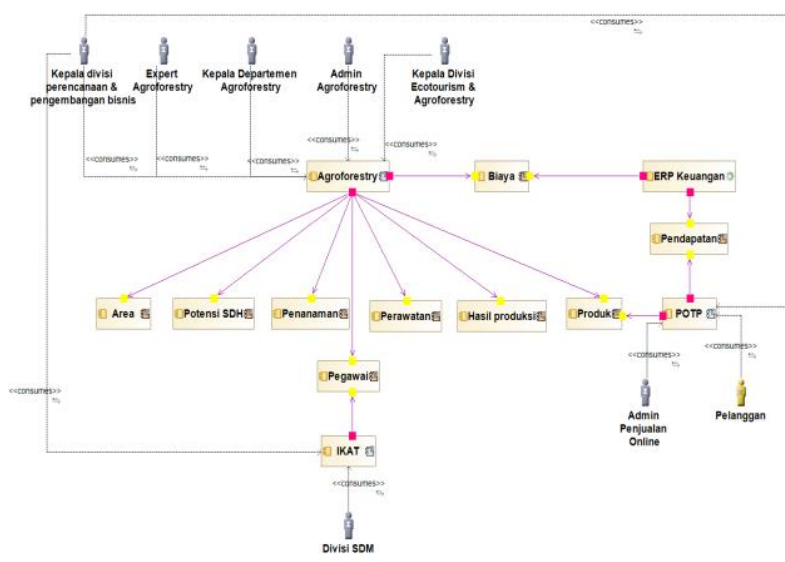

layanan yang dapat digunakan oleh pengguna sesuai dengan hak akses pengguna. Application Use-Case Diagram pada aplikasi agroforestry dapat dilihat pada Gambar 6 Application Use-Case Diagram.

Tabel 7 Interface Catalog

\begin{tabular}{|c|c|c|}
\hline \multirow{2}{*}{$\begin{array}{l}\text { Physical } \\
\text { Application } \\
\text { Componnet }\end{array}$} & Relationship & \multirow{2}{*}{$\begin{array}{c}\text { Physical } \\
\text { Application } \\
\text { Component }\end{array}$} \\
\hline & Interface & \\
\hline \multirow{3}{*}{ Agroforestry } & $\begin{array}{l}\text { Informasi produk siap } \\
\text { jual }\end{array}$ & POTP \\
\hline & $\begin{array}{c}\text { Informasi kebutuhan } \\
\text { biaya perencanaan }\end{array}$ & ERP Keuangan \\
\hline & $\begin{array}{c}\text { Informasi kinerja } \\
\text { pegawai pada divisi } \\
\text { agroforestry }\end{array}$ & IKAT \\
\hline POTP & $\begin{array}{c}\text { Informasi pendapatan } \\
\text { penjualan produk } \\
\text { agroforestry }\end{array}$ & ERP Keuangan \\
\hline
\end{tabular}

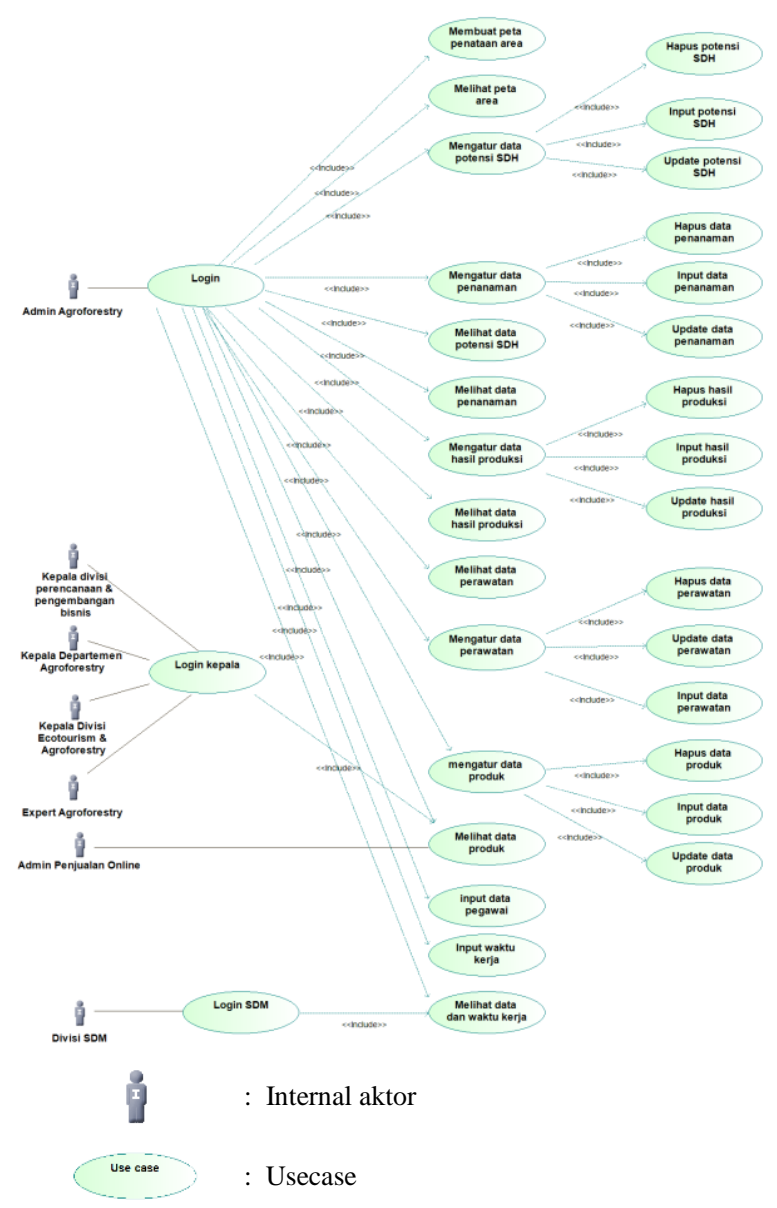

Gambar 6 Application Use-Case Diagram

\section{Kesimpulan}

Perancangan Enterprise Architecture untuk bagian agroforestry dapat dipetakan berdasarkan 3 arsitektur, yaitu bisnis, data dan aplikasi. Perancangan bisnis arsitektur berguna untuk memberikan kemudahan tercapainya tujuan dengan pertimbangan dari segi proses agar lebih efektif dan efisien. Pada arsitektur data target, diberikan rancangan kebutuhan data

Jurnal RESTI (Rekayasa Sistem dan Teknologi Informasi) Vol . 3 No. 2 (2019) 210 - 215 
berdasarkan arsitektur bisnis target. Data dari setiap proses dapat digunakan oleh proses lainnya dengan mudah. Dan pada arsitektur aplikasi target, di rancang sebuah aplikasi yang terintegrasi dengan aplikasi lainnya agar proses bisnis dapat lebih efektif dan efisien dan juga dapat melakukan pertukaran data dengan mudah.

Saran untuk penelitian selanjutnya adalah dapat meningkatkan integrasi untuk setiap bagian dalam perusahaan. Dan melanjutkan perancangan enterprise architecture ini sampai fase selanjutnya.

\section{Daftar Rujukan}

[1] Foorthuis, R., Van Steenbergen, M., Brinkkemper, S., \& Bruls, W.A. (2016). A theory building study of enterprise architecture practices and benefits. Information Systems Frontiers, 18(3), 541-546.
[2] The Open Group, 2011. TOGAF Version 9.1. U.S : Open Group Standard, ISBN: 978-90-8753-6.

[3] DESFRAY, Philippe; RAYMOND, Gilbert. Modelling enterprise architecture with TOGAF: A practical guide using UML and BPMN. Morgan, Kaufmann, 2014.

[4] Kurniawan, N. B. (2013, November). Enterprise Architecture design for ensuring strategic business IT alignment (integrating SAMM with TOGAF 9.1). In Rural Information \& Communication Technology and Electric-Vehicle Technology (rICT \& ICeV-T), 2013 Joint International Conference on (pp. 1-7). IEEE.

[5] Greefhorst, D., \& Proper, E. (2011). Architecture Principles, The Enterprise Engineering series, vol. 4.

[6] Kitsios, F., \& Kamariotou, M. (2018). Business strategy modelling based on enterprise architecture: a state of the art review. Business Process Management Journal.

[7] Bui, Q. (2017). Evaluating Enterprise Architecture Frameworks Using Essential Elements. Communications of the Association for Information Systems, 41(1), 6.

[8] Annual Report Perum Perhutani, Tahun 2017.

[9] Dorohyi, Y., Tsurkan, V., Telenyk, S., \& Doroha-Ivaniuk, O. (2017). A comparison enterprise architecture frameworks for critical IT infrastructure design. 